\title{
Grey Model Based Traffic Analysis on Car-hailing Platforms
}

\author{
Baiyu Chen ${ }^{\dagger}$ \\ College of Engineering \\ University of California Berkeley \\ Berkeley, CA 94720, USA \\ baiyu@berkeley.edu
}

\author{
Yuanxin Li \\ College of Engineering \\ Ocean University of China \\ Qingdao, China \\ 842708989@qq.com
}

\author{
Yi Kou \\ Dornsife College \\ University of Southern California \\ Los Angeles, CA, USA \\ yikou@usc.edu
}

\begin{abstract}
With the advent of self-driving and big data, travel through the internet based car-hailing platforms or apps will become the more common way. Based on the Grey Model (GM), this paper establishes the relationship between the network driver's vehicle quantity that can be dynamically adjusted and the corresponding capacity demand. The optimal driver's number can change accordingly with the change of the real time traveler's order and the online rate. As applied in a specific instance, through the model prediction, as of the end of 2018, the number of vehicles in the $Q$ city network reached 259,394 vehicles, an increase of $16.18 \%$ over the previous year. After 2019, the total amount of growth is more than ever, with an increase of about 490,000 vehicles in 2020 alone, a total increase of $21.85 \%$ from the end of 2017.
\end{abstract}

\section{CCS CONCEPTS}

- Hardware $\sim$ Wireless devices • Hardware $\sim$ Simulation and emulation

\section{KEYWORDS}

grey model, retain number, differential equation

\section{Introduction}

The rapid development of the Internet industry has made smart phones replace computers as the largest Internet terminals, and people's travel needs and methods have also undergone tremendous changes. With the addition of artificial intelligence [1-4], network-based era technologies [5-7], fast and simple travel has become the focus of passenger transportation. People now have more travel options to choose from, with the arrival of self-driving technology and big data, the future travel through the online car-hailing platform/apps will become the dominant. The rational formulation of the such process is the basis of an efficient internet based shared travel. The formulation of the

Permission to make digital or hard copies of all or part of this work for personal or classroom use is granted without fee provided that copies are not made or distributed for profit or commercial advantage and that copies bear this notice and the full citation on the first page. Copyrights for components of this work owned by others than ACM must be honored. Abstracting with credit is permitted. To copy otherwise, or republish, to post on servers or to redistribute to lists, requires prior specific permission and/or a fee. Request permissions from Permissions@acm.org.

AICS 2019, July 12-13, 2019, Wuhan, Hubei, China

(c) 2019 Association for Computing Machinery.

ACM ISBN 978-1-4503-7150-6/19/07...\$15.00

https://doi.org/10.1145/3349341.3349507 strategy depends on the network analysis of the traffic volume. At present, relevant research has just started.

The rapid development of artificial intelligence technology makes the self-driving car on the road just around the corner [58]. And needless to say, the emergence of autonomous vehicles will have a huge impact on traffic. For example, the specific navigation configuration from the unmanned vehicle [8-21], can make reasonable driving route changes to carry more passengers. Advancement in battery power and the health of the driver from smoke pollution and excessive sun shine and other factors [2235] makes the travel space wider and time longer. In fact, an efficient internet-based car hailing platform/app is not only reducing a lot of the transportation daily load, but also, with the development of cutting-edge AI technology, further scientific understanding of the natural environment, increased riskpreventing ability, improved system protection against attacks [36-40], it can be expanded to marine and air traffic. Vehicular wireless networks development enables the capability of artificial intelligence for dynamic traffic analysis [42-44]. It can be readily foreseeable that the future travel will surely become the dominant player in this industry, and only the travel mode that considers both the dynamic and static integration of time and space will be popular.

Based on the Grey Model, this paper establishes a model of the driver retain number for the internet-based car-hailing platforms/apps that can be dynamically adjusted according to the real time capacity demand. The optimal driver retain number can dynamically change with the changes in the traveller's order and the online rate, which provides the number of on-line drivers needed to meet the order and the need for improving customer stickiness. The mechanism for scientific and rigorous monitoring over the network car drivers can maximize the satisfaction of the car-hailing platform, and also that from both the drivers and the passengers.

\section{Theoretical Model for Simulating Car-hailing Driver Retain Number}

The most commonly used model is the $\operatorname{GM}(1,1)$ model: let $X^{(0)}=\left\{X^{(0)}(1), X^{(0)}(2), X^{(0)}(3), \cdots, X^{(0)}(n)\right\}$ be the original data of an indicator to be predicted. When the rank ratio of the series: $\lambda(t)=X^{(0)}(t-1) / X^{(0)}(t), t=2,3, \cdots, n$ all falls within the allowable coverage interval of $(\exp (-2 /(\mathrm{n}+1)), \exp (2 /(n+1))$, the GM $(1,1)$ model can be used for grey prediction. Otherwise, the data needs to be processed into a generated sequence. If you take a three-point smooth design of 
$X^{(0)}(t)=\left[X^{(0)}(t-1)+2 X^{(0)}(t)+X^{(0)}(t+1)\right] / 4 \quad, \quad$ After accumulating the processed data, a new sequence with reduced randomness and enhanced stationarity is obtained, which is called generating a series: $X^{(1)}=\left\{X^{(1)}(1), X^{(1)}(2), X^{(1)}(3), \cdots, X^{(1)}(n)\right\}$, the defined gray derivative for $X^{(1)}$ will then be:

$$
d(k)=X^{(0)}(k)=X^{(1)}(k)-X^{(1)}(k-1)
$$

Let $Z^{(1)}(k)$ be the adjacent average generating sequence:

$$
Z^{(1)}(k)=\left(X^{(1)}(k)+X^{(1)}(k-1)\right) / 2
$$

So the GM $(1,1)$ gray differential equation will be:

$$
X^{(0)}(k)+a Z^{(1)}(k)=b
$$

Among them, $X^{(0)}(k)$ is the gray derivative, $a$ is defined as the development coefficient, $Z^{(1)}(k)$ is defined as the whitening background, and $b$ is defined as the grey action amount.

Bring the moment $k=1,2,3, \cdots, n$ to the above style, we can get:

$$
X^{(0)}(i)+a Z^{(1)}(i)=b, i=1 \cdots n
$$

Before the next step, we introduce matrix vector notation:

$$
\begin{aligned}
& \hat{\alpha}^{T}=\left[\begin{array}{ll}
a & b
\end{array}\right], Y_{n}^{T}=\left[\begin{array}{llll}
X^{(0)}(2) & X^{(0)}(3) & \cdots & X^{(0)}(n)
\end{array}\right] \\
& B_{n}{ }^{T}=\left[\begin{array}{cccc}
-Z^{(1)}(2) & -Z^{(1)}(3) & \cdots & -Z^{(1)}(n) \\
1 & 1 & \cdots & 1
\end{array}\right]
\end{aligned}
$$

Then the GM $(1,1)$ model can be expressed as:

$$
Y_{n}=B_{n} \hat{a}
$$

Estimate the values of $a$ and $b$ obtained by the least squares method:

$$
\hat{a}^{T}=\left[\begin{array}{ll}
a & b
\end{array}\right]=\left[\left(B_{n}^{T} B_{n}\right)^{-1} B_{n}^{T} Y_{n}\right]^{T}
$$

Bring (6) into equation (3) and solve the differential equation:

$$
\hat{X}^{(1)}(t+1)=\left[X^{(0)}(1)-b / a\right] e^{-a t}+b / a, t=1,2, \cdots, n-1
$$

$\hat{X}^{(1)}(t+1)$ is the obtained accumulated predicted value, the corresponding inverse transform is performed to obtain the actual predicted value, which is:

$$
\hat{X}^{(0)}(t+1)=\hat{X}^{(1)}(t+1)-\hat{X}^{(1)}(t), t=1,2, \cdots, n-1
$$

In special cases, $k=1,2,3, \cdots, n$ will be treated as a continuous variable $t$, and the previous $X^{(1)}$ can be regarded as a function of time $t$, so the gray derivative $X^{(0)}(t)$ becomes the derivative of the continuous function $d X^{(1)}(t) / d t$, and the whitened background value $Z^{(1)}(k)$ corresponds to the derivative $X^{(1)}(t)$. Then the white differential equation corresponding to the gray differential equation of GM $(1,1)$ can be formulated as:

$d X^{(1)}(t) / d t+a X^{(1)}(t)=b$

\section{Applying Grey Model for Real Car-hailing Data from $Q$ City in China}

To fully evaluate the accuracy and the utilize the power of the aforementioned grey modelling simulation, we have applied it to a real time online car-hailing data from China's $Q$ city.

Table 1 and Figure 1 are the original data of the number of car drivers in Q City in 2012-2016:

\section{Table 1: Driver retain number}

\begin{tabular}{|l|l|l|l|}
\hline Year & 2010 & 2011 & 2012 \\
\hline Retain number/10k & 73 & 89 & 105 \\
\hline 2013 & 2014 & 2015 & 2016 \\
\hline 125 & 144 & 168 & 191 \\
\hline
\end{tabular}

As can be seen from Figure 1, the total number of contracted vehicles continues to grow, especially in the past three years. In the following, through the GM $(1,1)$ grey prediction model, the grey forecast of the $Q$ city online car-hailing ownership in the next few years will be made. Firstly, the Q-city network car ownership statistics data sequence is established as follows: $X^{(0)}=\left(X^{(0)}(1), \cdots, X^{(0)}(7)\right)=(73,89,105,125,144,168,191)$, the level ratio $\lambda(t) \quad$ is: $\lambda(t)=(\lambda(2), \lambda(3), \cdots, \lambda(7))=(0.8202,0.8476,0.8400$, $0.8681,0.8571,0.8796)$, Obviously, $\lambda(t), t=1,2, \cdots, 7$ .all fall within the allowable coverage interval of $(0.7788,1.2840)$, so the GM $(1,1) S$ model can be established for grey prediction. After the original data is accumulated as $X^{(1)}=(73,162,267,392,536,704,895)$, construct the data vector $Y$ and the data matrix $B$, and calculate them separately as $\left(B^{T} B\right)^{-1}, B^{T} Y$, we have:

$Y^{T}=\left[\begin{array}{llll}89 & 105 & \cdots & 191\end{array}\right], \quad B^{T}=\left[\begin{array}{cccc}-117.5 & -214.5 & \cdots & -799.5 \\ 1 & 1 & \cdots & 1\end{array}\right]$, and $\left(B^{T} B\right)^{-1}=\left[\begin{array}{cc}0 & 0.0013 \\ 0.0013 & 0.7156\end{array}\right], \quad B^{T} Y=\left[\begin{array}{c}-397848 \\ 822\end{array}\right] \cdot \hat{a}^{T}=[-0.1500,73.3541]$

can be known from the formula $\hat{\alpha}=\left(B^{T} B\right)^{-1} B^{T} Y$. And thus model parameters can be calculated as: $a=-0.15, b=73.3541$. And since $-a \leq 0.3$, the $\mathrm{GM}(1,1)$ model can therefore be used for medium and long-term prediction, from

$d X^{(1)} / d t-0.15 X^{(1)}=73.3541$

We can solve the differential equation as follows:

$\hat{X}^{(1)}(t+1)=\left[X^{(0)}(1)-b / a\right] e^{-a t}+b / a=562.0273 \mathrm{e}^{0.15 t}-489.0273$ 
From (8) to make the corresponding inverse transformation, get the actual predicted value of the Q-city 2012-2016 online carhailing driver retain number

$$
\hat{X}^{(0)}=\left(\hat{X}^{(0)}(1), \hat{X}^{(0)}(2), \cdots, \hat{X}^{(0)}(7)\right)=(73.0000,90.9626,105.6835 \text {, }
$$$$
122.7867,142.6578,165.7447,192.5679)
$$

Calculate the residual as $\varepsilon(t)=X^{(0)}(t)-\hat{X}^{(0)}(t), t=1,2, \cdots, n$, and the relative error as $\Delta_{t}=\left|\varepsilon(t) / X^{(0)}(t)\right|, t=1,2, \cdots, n$, we can get the GM $(1,1)$ model accuracy test level and test results, as shown in Table 2 and 3:

\section{Table 2: Accuracy test level}

\begin{tabular}{|c|c|c|}
\hline Accuracy level & 1st & 2nd \\
\hline Relative error & 0.01 & 0.02 \\
\hline Accuracy level & 3rd & 4 th \\
\hline Relative error & 0.10 & 0.20 \\
\hline
\end{tabular}

Table 3: Test result

\begin{tabular}{|c|c|c|c|c|c|}
\hline \multirow{2}{*}{ No. } & \begin{tabular}{|l} 
Actual \\
data
\end{tabular} & $\begin{array}{l}\text { Simulate } \\
\text { data }\end{array}$ & Residual & Relative error & \multirow{2}{*}{$\begin{array}{l}\text { Accurac } \\
\text { y level }\end{array}$} \\
\hline & $X^{(0)}(t)$ & $\hat{X}^{(0)}(t)$ & $\varepsilon(t)=X^{(0)}(t)-\hat{X}^{(0)}(t)$ & $\left|\Delta_{t}=\right| \varepsilon(t) / X^{(0)}(t) \mid$ & \\
\hline 1 & 73 & 73.000 & 0 & 0 & $1 \mathrm{st}$ \\
\hline 2 & 89 & 90.9626 & -1.9626 & 0.0221 & 2nd \\
\hline 3 & 105 & 105.6835 & -0.6835 & 0.0065 & 1 st \\
\hline 4 & 125 & 122.7867 & 2.2133 & 0.0177 & 2nd \\
\hline 5 & 144 & 142.6578 & 1.3422 & 0.0093 & $1 \mathrm{st}$ \\
\hline 6 & 168 & 165.7447 & 2.2553 & 0.0134 & 2nd \\
\hline 7 & 191 & 192.5679 & -1.5679 & 0.0082 & $1 \mathrm{st}$ \\
\hline
\end{tabular}

When the coefficient of development of the GM(1,1) model is $|a| \geq 2$, the $\operatorname{GM}(1,1)$ model has no significance in prediction; when $|a|<2$, the $\operatorname{GM}(1,1)$ model is meaningful, and the prediction effect will vary depending on different values of $a$, as shown in Table 4:

Table 4: prediction effect

\begin{tabular}{|c|c|c|}
\hline $\begin{array}{c}a \text { range values } \\
\text { GM (1,1) } \\
\text { prediction effect }\end{array}$ & $\begin{array}{c}\text { Mid and long } \\
\text { term }\end{array}$ & $\begin{array}{c}\text { Caution should be } \\
\text { taken for Mid and } \\
\text { long term }\end{array}$ \\
\hline $0.5<-a<0.8$ & $0.8<-a<1$ & $-a>1$ \\
\hline $\begin{array}{c}\text { Caution should be } \\
\text { taken for short term }\end{array}$ & $\begin{array}{c}\text { Rectify by the } \\
\text { residual model }\end{array}$ & $\begin{array}{c}\text { Should not be applied } \\
\text { for prediction }\end{array}$ \\
\hline
\end{tabular}

It can be seen from Table 4 that the accuracy level is at least the second level, and it is easy to know that the model has high precision with reference to Table 2. From formula (8) and formula (11), the predicted value of the vehicle car ownership in 2017-2025 can be obtained. See Table 5.
Table 5: Predicted values

\begin{tabular}{|l|l|l|l|l|}
\hline Year & 2017 & 2018 & 2019 & 2020 \\
\hline $\begin{array}{l}\text { Retain } \\
\text { number/10k }\end{array}$ & 223.7319 & 259.9394 & 302.0065 & 350.8815 \\
\hline 2021 & 2022 & 2023 & 2024 & 2025 \\
\hline 407.6662 & 473.6405 & 550.2918 & 639.3478 & 742.8162 \\
\hline
\end{tabular}

The sharing of road resources between self-driving and private cars is the future transportation trend for the small cities. As shown in Figure 2, in China's $Q$ city for instance, the total number of online car-hailing vehicles will continue to grow. This example shows that by the end of 2018, Q-city online car-hailing has reached $259,394,400$ vehicles, an increase of $16.18 \%$ over the previous year. In particular, after 2019, the total amount of growth is much higher than in the past. In 2020 alone, it increased by about 490,000 units, an increase of $21.85 \%$ from the end of 2017. The number of drivers in online hailing industry is forecasted to ensure the analysis of the traffic volume of the whole city's transportation network.

\section{Conclusions and Future Application}

The online car-hailing is a new thing that keeps evolving. With the advancement of cutting-edge science and machine learning technology and the improvement of the legal provisions for the industry, the era of shared roads between self-driving cars and private cars is bound to emerge [45-47]. The online car-hailing driver/user prediction model can provide more options for passengers to plan to travel to make up for the inconvenience of public transportation, and can also provide a theoretical basis for the development of specific strategies for the online platform/apps.

\section{REFERENCES}

[1] H.J. ESCALANTE, V. PONCE-LÓPEZ, J. WAN, et al. 2016. ChaLearn Joint Contest on Multimedia Challenges Beyond Visual Analysis: An overview. 2016 23rd International Conference on Pattern Recognition (ICPR), 67-73.

[2] B. Chen, Z. Yang, S. Huang, X. Du, Z. Cui, J. Bhimani, et al. 2017. Cyberphysical system enabled nearby traffic flow modelling for autonomous vehicles. 36th IEEE International Performance Computing and Communications Conference, Special Session on Cyber Physical Systems: Security, Computing, and Performance (IPCCC-CPS) IEEE.

[3] B. Anthony, B.Y. Chen. How Emerging Technologies Could Transform Infrastructure. http://www.governing.com/gov-institute/voices/col-hyperlaneemerging-technologies-transform-infrastructure.html.

[4] V. PONCE-LÓPEZ, B. CHEN, M. OLIU, et al. 2016. ChaLearn LAP 2016: First Round Challenge on First Impressions - Dataset and Results. Computer Vision - ECCV 2016 Workshops. Springer, Cham, 400-418.

[5] B. CHEN, S. ESCALERA, I. GUYON, et al. 2016. Overcoming Calibration Problems in Pattern Labeling with Pairwise Ratings: Application to Personality Traits. Computer Vision - ECCV 2016 Workshops. Springer, Cham, 419-432.

[6] S.F. Zhang, W. Shen, D.S. Li, X.W. Zhang, B.Y. Chen (2018). Nondestructive ultrasonic testing in rod structure with a novel numerical Laplace based wavelet finite element method. Latin American Journal of Solids and Structures, 15(7):1-17, e48.

[7] B. Chen, B. Wang (2017). Location Selection of Logistics Center in e-Commerce Network Environments. American Journal of Neural Networks and Applications, Science Publishing Group, 3(4): 40-48.

[8] L.P. Wang, B.Y. Chen, C. Chen, Z.S. Chen, G.L. Liu (2016). Application of linear mean-square estimation in ocean engineering. China Ocean Eng. Chinese Ocean Engineering, 30: 149-160.

[9] X. Liu, Y. He, H. Fu, B. Chen, M. Wang, Z. Wang. 2018. How Environmental Protection Motivation Influences on Residents' Recycled Water Reuse Behaviors: A Case Study in Xi'an City. Water, 10, 1282. 
[10] X. Liu, Y. He, H. Fu, B. Chen, M. Wang. Scientometric of Nearly Zero Energy Building Research: A Systematic Review from the Perspective of Co-Citation Analysis. Journal of Thermal Science.

[11] S. Jiang, M.J. Lian, C.W. Lu, S.L. Ruan, Z. Wang, B.Y. Chen. SVM-DS fusion based soft fault detection and diagnosis in solar water heaters, Energy Exploration \& Exploitation, DOI: 10.1177/0144598718816604.

[12] J. Song, Q. Feng, X. Wang, H. Fu, W. Jiang, B. Chen (2019). Spatial Association and Effect Evaluation of $\mathrm{CO} 2$ Emission in the Chengdu-Chongqing Urban Agglomeration: Quantitative Evidence from Social Network Analysis. Sustainability, 2019, 11, 1.

[13] L.P. Wang, B. Chen, J.F. Zhang, Z. Chen (2013). A new model for calculating the design wave height in typhoon-affected sea areas. Natural Hazards. Springer Netherlands, 67: 129-143.

[14] B. Chen, G. Liu, L. Wang (2017). Predicting Joint Return Period Under Ocean Extremes Based on a Maximum Entropy Compound Distribution Model. International Journal of Energy and Environmental Science, 2(6): 117-126.

[15] L. Wang, X. Xu, G. Liu, B. Chen, Z. Chen. 2017. A new method to estimate wave height of specified return period. Chin J Oceanol Limnol. Science Press, 35: 1002-1009.

[16] B.Y. Chen, G.L. Liu, J.F. Zhang et al. 2016. A calculation method of design wave height under the three factors of typhoon: China, ZL 20161 0972118.X. Patent, 10-31.

[17] L.P. Wang, G.L. Liu, B.Y. Chen et al. 2013. Typhoon influence considered method for calculating combined return period of ocean extreme value: China, ZL 20101 0595807.6. Patent, 03-20.

[18] G.L. Liu, Z.J. Zheng, L.P. Wang, et al. 2017. Power-type wave absorbing device and using method thereof: China, ZL 20151 0575336.5. Patent, 11-03.

[19] L.P. Wang, G.L. Liu, B.Y. Chen, et al. 2015. Typhoon based on the principle of maximum entropy waters affect the design wave height calculation method: China, ZL 20101 0595815.0. Patent, 2015-08-19.

[20] G. Liu, B. Chen, L. Wang, et al. (2018) Wave Height Statistical Characteristic Analysis. Journal of oceanology and limnology, 36(4):1123-1136.

[21] B.Y. Chen, G.L. Liu, L.P. Wang, K.Y. Zhang, S.F. Zhang. 2019. Determination of Water Level Design for an Estuarine City. Journal of oceanology and limnology. https://doi.org/10.1007/s00343-019-8107-z

[22] Y. Cheun, Y. Kou, B. Stevenson, H.K. Kim, M.C. Koag, S. Lee. 2013. Synthesis of C17-OH-north unit of ritterazine G via "Red-Ox" modifications of hecogenin acetate. Steroids, 78: 639-643

[23] Y. Kou, S. Lee (2013). Unexpected opening of steroidal E-ring during hypoiodite-mediated oxidation. Tetrahedron Lett, 54: 4106-4109.

[24] Y. Kou, Others. 2015. Structural and kinetic study of N7-methyl, N7-benzyl and C8-chloro guanine lesions using human DNA polymerase $\beta$ [Internet]. Available: https://repositories.lib.utexas.edu/handle/2152/46815

[25] S. Lee, Y. Kou, M. Koag. Mechanism of alkylation and platination-induced mutagenesis. ENVIRONMENTAL AND MOLECULAR MUTAGENESIS 59, $107-$ 107.

[26] Y. Kou, M.C. Koag, S. Lee. 2015. N7 methylation alters hydrogen-bonding patterns of guanine in duplex DNA. J Am Chem Soc, 137: 14067-14070.

[27] Y. Cheun, M.C. Koag, Y. Kou, Z. Warnken, S. Lee. 2012. Transetherificationmediated E-ring opening and stereoselective "Red-Ox" modification of furostan. Steroids, 77: 276-281.

[28] X. Lei, Y. Kou, Y. Fu, N. Rajashekar, H. Shi, F. Wu, et al. 2018. The cancer mutation D83V induces an $\alpha$-helix to $\beta$-strand conformation switch in MEF2B. J Mol Biol. 2018; doi: 10.1016/j.jmb. 02.012

[29] X. Lei, H. Shi, Y. Kou, N. Rajashekar, F. Wu, C. Sen, et al. (2018). Crystal Structure of Apo MEF2B Reveals New Insights in DNA Binding and Cofactor Interaction. Biochemistry, 57: 4047-4051.

[30] M.C. Koag, Y. Kou, H. Ouzon-Shubeita, S. Lee (2014). Transition-state destabilization reveals how human DNA polymerase $\beta$ proceeds across the chemically unstable lesion N7-methylguanine. Nucleic Acids Res, 42: 87558766.

[31] Y. Yang, L. Chen, H.Z. Pan, Y. Kou, C.M. Xu. 2009. Glycosylation modification of human prion protein provokes apoptosis in HeLa cells in vitro. BMB Rep, 42: 331-337.

[32] M.C. Koag, Y. Cheun, Y. Kou, H. Ouzon-Shubeita, K. Min, A.F. Monzingo, et al. 2013. Synthesis and structure of 16,22-diketocholesterol bound to oxysterol$\begin{array}{llll}\text { binding protein } & \text { Osh4. } & \text { Steroids, } & \text { 78: }\end{array}$
[33] Y. Kou, M.C. Koag, Y. Cheun, A. Shin, S. Lee. 2012. Application of hypoiodite mediated aminyl radical cyclization to synthesis of solasodine acetate. Steroids, 77: 1069-1074.

[34] Y. Kou, Y. Cheun, M.C. Koag, S. Lee. 2013. Synthesis of $14^{\prime}, 15^{\prime}$-dehydroritterazine $\mathrm{Y}$ via reductive and oxidative functionalizations of hecogenin acetate. Steroids, 78: 304-311.

[35] Y. Kou, M.C. Koag, S. Lee (2018). Structural and Kinetic Studies of the Effect of Guanine N7 Alkylation and Metal Cofactors on DNA Replication. Biochemistry, 57: 5105-5116.

[36] B.Y. Chen, K.Y. Zhang, L.P. Wang, S. Jiang, G.L. Liu. 2019. Generalized Extreme Value - Pareto Distribution Function and Its Applications in Ocean Engineering, Chinese Ocean Engineering, 2.

[37] Y. Chen, Z. Wang, D. Whalley, L. Lu. 2016. Remix. On-demand live randomization. In Proceedings of the Sixth ACM Conference on Data and Application Security and Privacy 2016 Mar 9 (pp. 50-61). ACM.

[38] Y. Zhou, X. Wang, Y. Chen, Z. Wang. 2014. Armlock. Hardware-based fault isolation for arm. InProceedings of the 2014 ACM SIGSAC Conference on Computer and Communications Security 2014 Nov 3, 558-569. ACM.

[39] X. Wang, Y. Chen, Z. Wang, Y. Qi, Y. Zhou. 2015. SecPod. a Framework for Virtualization-based Security Systems. In USENIX annual technical conference Jul 8, 347-360.

[40] X. Wang, Y. Qi, Z. Wang, Y. Chen, Y. Zhou. 2017. Design and implementation of SecPod, a framework for virtualization-based security systems. IEEE Transactions on Dependable and Secure Computing. Mar 2.

[41] Y. Chen, Y. Zhang, Z. Wang, T. Wei. 2017. Downgrade Attack on TrustZone. arXiv preprint arXiv:1707.05082. Jul 17.

[42] P. Cui, M. Tonnemacher, D. Rajan, J. Camp, WhiteCell. 2015. Energy-efficient use of unlicensed frequency bands for cellular offloading. In Proceedings of 2015 IEEE International Symposium on Dynamic Spectrum Access Networks (DySPAN), Stockholm, Sweden, 29 Sept.-2 Oct. 2015; IEEE:Piscataway, NJ, 188 199.

[43] P. Cui, H. Liu, D. Rajan, J. Camp. 2014. A measurement study of white spaces across diverse population densities. In Proceedings of 2014 12th International Symposium on Modeling and Optimization in Mobile, Ad Hoc, and Wireless Networks (WiOpt), 12-16 May, Hammamet, Tunisia

[44] P. Cui, S. Chen, J. Camp, GreenLoading. Using the Citizens Band Radio for Energy-Efficient Offloading of Shared Interests. In Proceedings of the 21st ACM International Conference on Modeling, Analysis and Simulation of Wireless and Mobile Systems.

[45] J. Xu, L. Huang, L. Yang (2017). Magnetic transforms of modulus type applied at region of lower latitudes in SE China. Journal of Applied Geophysics, 139: 188-194.

[46] J. Xu, Z. Shen, Q. Ren (2017) Simulation analysis of low strain dynamic testing of pile with inhomogeneous elastic modulus. Journal of Measurements in Engineering, 5(3): 138-148.

[47] J. Xu, Q. Ren, Z. Shen (2017). Sensitivity analysis of the influencing factors of slope stability based on LS-SVM. Geomechanics and Engineering, 13(3): 447458 . 